$11-19-2011$

\title{
Non-operative management is superior to surgical stabilization in spine injury patients with complete neurological deficits: $A$ perspective study from a developing world country, Pakistan
}

Muhammad Shahzad Shamim

Aga Khan University, shahzad.shamim@aku.edu

Syed Faizan Ali

Aga Khan University

Ather Enam

Aga Khan University, ather.enam@aku.edu

Follow this and additional works at: https://ecommons.aku.edu/pakistan_fhs_mc_surg_neurosurg

Part of the Neurology Commons, Neurosurgery Commons, and the Surgery Commons

\section{Recommended Citation}

Shamim, M., Ali, S., Enam, A. (2011). Non-operative management is superior to surgical stabilization in spine injury patients with complete neurological deficits: A perspective study from a developing world country, Pakistan. Surgical Neurology International, 2, 166.

Available at: https://ecommons.aku.edu/pakistan_fhs_mc_surg_neurosurg/30 


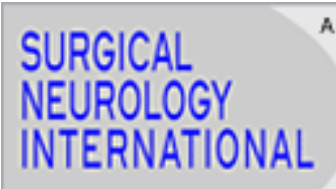

AN OPEN ACCESS, INTERNATIONAL JOURNAL OF NEUROSURGERY AND NEUROSCIENCES

Home | Browse articles | Instructions | Submit articles

Surg_Neurol Int. 2011; 2: 166.

PMCID: PMC3229809

Published online 2011 Nov 19. doi: $10.4103 / 2152-7806.90027$

\section{Non-operative management is superior to surgical stabilization in spine injury patients with complete neurological deficits: A perspective study from a developing world country, Pakistan}

Muhammad Shahzad Shamim, Syed Faizan Ali, and Syed Ather Enam ${ }^{*}$

Department of Surgery, Section of Neurosurgery, Aga Khan University Hospital, Karachi 74800, Pakistan

Muhammad Shahzad Shamim: shahzad.shamim@aku.edu; Syed Faizan Ali: fiq200best@gmail.com; Syed Ather Enam: fiq200best@hotmail.com

* Corresponding author

Received 2010 Dec 13; Accepted 2011 Sep 27.

Copyright : @ 2011 Shamim MS.

This is an open-access article distributed under the terms of the Creative Commons Attribution License, which permits unrestricted use, distribution, and reproduction in any medium, provided the original author and source are credited.

This article has been cited by other articles in PMC.

\section{Abstract}

Go to:

\section{Background:}

Surgical stabilization of injured spine in patients with complete spinal cord injury is a common practice despite the lack of strong evidence supporting it. The aim of this study is to compare clinical outcomes and cost-effectiveness of surgical stabilization versus conservative management of spinal injury in patients with complete deficits, essentially from a developing country's point of view.

\section{Methods:}

A detailed analysis of patients with traumatic spine injury and complete deficits admitted at the Aga Khan University Hospital, Pakistan, from January 2004 till January 2010 was carried out. All patients presenting within 14 days of injury were divided in two groups, those who underwent stabilization procedures and those who were managed non-operatively. The two groups were 

compared with the endpoints being time to rehabilitation, length of hospital stay, 30 day morbidity/mortality, cost of treatment, and status at follow up.

\section{Results:}

Fifty-four patients fulfilled the inclusion criteria and half of these were operated. On comparing endpoints, patients in the operative group took longer time to rehabilitation $(P$-value $=0.002)$; had longer hospital stay $(P$-value $=0.006)$ which included longer length of stay in special care unit $(P$-value $=0.002)$ as well as intensive care unit $(P$-value $=0.004)$; and were associated with more complications, especially those related to infections $(P$-value $=0.002)$. The mean cost of treatment was also significantly higher in the operative group (USD 6,500) as compared to non-operative group (USD 1490) $(P$-value $<0.001)$.

\section{Conclusion:}

We recommend that patients with complete SCI should be managed non-operatively with a provision of surgery only if their rehabilitation is impeded due to pain or deformity.

Keywords: Complete neurological deficits, spinal cord injuries, surgical stabilization

\section{INTRODUCTION}

Complete spinal cord injury or complete deficits following spine injury are irreversible.[20] A few authors have reported some improvement in these patients but that can be attributed more to an incomplete examination rather than complete nature of injury. $[\underline{5}, \underline{14}, \underline{16}, \underline{19}, \underline{21}]$ Management of these patients therefore revolves around prevention of complications, early re-habilitation, and reintegration into society. Surgical fixation of spine in these patients is a very common practice and has been advocated for stabilization of unstable spine, promotion of early re-habilitation, reduction of hospital stay, and prevention of progressive deformity.[11, $\underline{26}, \underline{34}]$ However, none of these objectives have been convincingly shown to be facilitated by surgical intervention. $[\underline{1}-\underline{4}, \underline{8}, \underline{10}, \underline{12}, \underline{13}, \underline{30}]$ In contrast, several authors have advocated non-operative management of these patients showing outcomes either comparable or superior to patients who undergo surgical stabilization.[1] A cochrane review on this subject has also been inconclusive about either benefits or harms of surgical stabilization.[1] With reference to patients with complete deficits in particular, the need for surgery has remained even more controversial.[23 $\underline{28}, \underline{33}]$ We hypothesized that in patients with complete deficits following spinal injury, non-operative management is superior to operative management in terms of both clinical outcomes and cost effectiveness, especially considering the factors involved in the management of patients in a developing world country like Pakistan.

\section{MATERIALS AND METHODS}

We performed retrospective review of charts and departmental inpatient records from January 2004 to January 2008 and then onwards prospectively till January 2010. All patients admitted in the Aga Khan University Hospital, Pakistan, with "complete 

injury", i.e. patients with either complete SCI or complete deficits following traumatic spine injury presenting within 14 days of injury were included. Complete SCI was defined as patients having no motor or sensory function below the neurological level, no preserved function in sacral segments S4-S5 (ASIA A),[7] and confirmed on the basis of MRI of affected region showing complete disruption of spinal canal. Patients with injuries higher than $\mathrm{C} 4 / 5$ or those with significant associated injuries such as chest, abdominal, or pelvic injuries were excluded. Patients' demographic data, history pertaining to the trauma, hospital course, and follow ups were recorded on a two-page standardized proforma. Included patients were divided into two groups, those who underwent surgical stabilization procedures and those who were managed non-operatively. The two groups were compared using five outcome parameters: (1) time to rehabilitation, (2) length of hospital stay, (3) 30 day morbidity, mortality, (4) cost of treatment, and (5) status at follow up. Rehabilitation was defined as mobilization from bed up to chair or wheelchair and status at follow up was measured in terms of axial pain on mobilization at follow up. The data collected was entered and analyzed using Statistical Package for Social Sciences (SPSS) version 16.0. Results are expressed as mean \pm standard deviation for continuous variables such as age, duration of symptoms, operative time, hospital stay, cost, etc. For categorical data, such as complications, pain on ambulation, etc, frequency and percentage were utilized. Complications were also measured using stratified analysis, grouping the complications as infections related, stasis related, and others. The two groups were compared using independent sample Student's t-test for continuous variables and chi square for categorical data. A $P$-value $<0.05$ was considered significant.

\section{RESULTS}

Go to:

We received a total of 294 patients with some form of spine injury over the 6-year study period but only 62 of these patients had complete injuries. Of these 62 patients, a further 8 were excluded, 3 due to delayed presentation, 3 due to severity of associated injuries and 2 that left the hospital against medical advice. The total number of patients included in our study was therefore 54, of which $34(63 \%)$ were enrolled prospectively. There were 42 male and 12 female patients and the mean age of patients was 34 years which was comparable in the two groups (range 16-72). The mean time from injury to presentation was $53.4 \mathrm{~h}$ although 17 patients presented within $12 \mathrm{~h}$ of injury. Twenty-four (44\%) patients were administered steroids on presentation, as per guidelines based on NASCIS trials, but continued inconsistently.[31] None of the patients received steroids beyond $24 \mathrm{~h}$ of admission. Road traffic accident (RTA) (52\%) was the most common etiology followed by fall from heights (33\%); 26 patients (48\%) had cervical spine or cervico-dorsal junction injury, 15 (28\%) had dorsal spine and 13 (24\%) had dorso-lumbar junction or lumbar spine injury; there were 37 fracture dislocations, 10 burst fractures, and 7 patients with a minor fracture which was defined as a fracture involving one column and with no apparent dislocation.

Twenty-seven patients underwent stabilization procedures and an equal number were managed without surgery; the demographic variables of the two groups including revised trauma score (RTS) and abbreviated injury scores (AIS) were comparable. Anterior decompression and fusion was the most common surgical procedure performed in 10 patients; the mean time from presentation to surgical stabilization was 6.8 days ( $3 \mathrm{~h}$ to 30 days); the mean duration of surgery was 142 min (120-360 min); the mean intraoperative blood transfusion was less than one unit of packed cell and there were no intra-operative or immediate post-operative complications; the mean time from presentation to rehabilitation was 5 days and the mean length of hospital stay was 17 days for 
all patients. The group wise details are presented in Tables $\underline{1}$ and $\underline{2}$. The mean intensive care unit (ICU; very high dependency units with ventilators, invasive monitoring, and one on one nursing) stay was 4 days, special care unit (SCU; step down/ intermediate care units without provisions for mechanical ventilation but with one hourly non-invasive monitoring and two on five nursing) stay was 3 days and stay in regular ward (four hourly monitoring, one on six to ten nursing) was 9.8 days. There were 42 documented complications in 23 patients (26 in the operative group and 16 in the non-operative group) most common of which were urinary tract infections, pneumonia, and decubitus ulcers [Table 3]. Five patients expired during hospital stay, three due to sepsis leading to multi-organ failure, one due to a probable pulmonary embolism, and one due to a massive myocardial infarction. Twenty-one of 49 patients discharged alive could be followed for a mean duration of 9 months. All except 1 of these patients were alive, 15 were asymptomatic but 5 complained of persistent pain at operative site. Of these 21 patients with available follow ups, all of the 10 patients managed non-operatively had no complaints of fracture site pain but in contrast, only 5 of 10 patients who were operated, were pain free. The mean cost of treatment during hospitalization was USD 4,100. On comparison of the two groups, patients in the operative group took longer time to rehabilitation with a mean of 7.5 days compared to 2.13 days $(P$-value $=0.002)$, had longer hospital stay $(P$-value $=0.006)$ which included longer length of stay in special care unit $(P$-value $=0.002)$ as well as ICU $(P$-value $=0.004)$; and were associated with more infection-related complications $(P$-value $=0.0027)$. The mean cost of treatment was also significantly higher in the operative group (USD 6,500) as compared to non-operative group (USD 1490) $(P$-value $<0.001)$. A comparison of study endpoints is tabled in Table 4.

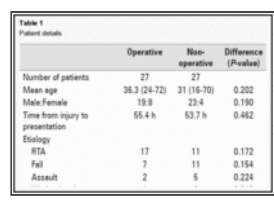

\section{Table 1}

Patient details

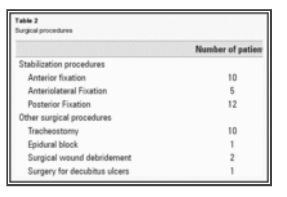

\section{Table 2}

Surgical procedures

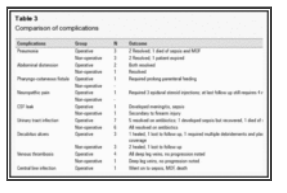

\section{Table 3}

Comparison of complications

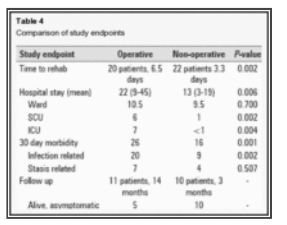

\section{Table 4}

Comparison of study endpoints 
Surgical stabilization of patients with complete SCI is a common procedure in most spine centers of the world. Several authors have argued for a non-operative management of these patients but spine surgeons around the world continue to offer surgical stabilization on the basis of "perceived" advantages, such as early re-habilitation, shorter hospital stay, and prevention of progressive spine deformity.[1] A recent intervention review conducted by the Cochrane Collaboration aimed to address both the effectiveness and cost-effectiveness of surgical fixation in SCI, but remained inconclusive due to dearth of quality studies with good sample size.[1] The current study has the largest comparable group of patients with spine injury and complete deficits, and is the first study which compares clinical outcomes as well as cost effectiveness of surgical stabilization in these patients.

Indications for surgical stabilization remain subjective.[1] In the absence of evidence-based guidelines, the choice of managing spinal injury patients with complete deficits at our center rests on the preference of the spine surgeon. We had six spine surgeons in our team at the time of conduction of this study and the opinion regarding the need for surgical stabilization in complete SCI was equally divided. Consequently, approximately half the patients underwent stabilization procedures and half were managed non-operatively, which provided a perfect opportunity to conduct this study. Part of the data was collected through review of medical records, and remaining was collected prospectively. Spine surgeons barring the senior author (SAE) were not informed of the ongoing data collection to prevent bias. The two groups are comparable except for the anatomical level of injuries. The operative group comprised of relatively more patients with injuries involving cervico-dorsal junction and the non-operative group comprised of more patients with involvement of dorsal spine; however, the difference was not statistically significant.

Much has been published in the debate for and against stabilization in spinal cord injuries.[1] For incomplete spinal cord injuries, a case can be made for surgical stabilization as a means for preventing further injury to neural elements although the same logic does not apply to injuries which are already complete. Similarly, it is argued that rehabilitation may be started earlier with surgical stabilization in patients with incomplete injuries. Same argument cannot be applied for patients with complete injuries since immediate rehabilitation may be initiated with external bracing at no risk of causing additional injury, as long as pain is not a limiting factor. Progressive spinal deformity and axial back pain, the other reasons for advocating surgery, may also be prevented by surgical stabilization although no literature exists to support this notion. Our results also suggest that patients who do not undergo stabilization procedures do not necessarily experience axial back pain on mobilization as none of the 10 patients in the non-operative group reported any back pain at 3-month mean follow up.

We have shown that managing these patients without surgery leads not only to a significant reduction in complications, mortality, time to rehabilitation, cost, and hospital stay, but also better outcomes at 9-month follow up. Our conclusions have global implication but they imply even more to under developed countries with limited resources available to patients. In underdeveloped countries, cost of instrumentation is tremendous, compared to per capita income, infection rates are high, rehabilitation centers are few, and follow up is poor.[27, 29, 30, 32] The mean cost incurred for surgical stabilization at our center was USD 6500, which is enormous in the background of USD 846 per capita GDP of our country. Such expenditure appears unjustified for a procedure which does not have evidence proven advantage in any way. 
There are a few limitations in our study. The follow up of our patients is inadequate as only 21 of 49 patients discharged alive could be followed for a mean follow up of 9 months. Published reports from a different region of our country also show poor follow up (4-6 weeks) of SCI patients.[27, 29, $\underline{32}]$ We did not repeat imaging except for plain X-rays at follow up for patients managed non-operatively as none of them were symptomatic. The frequency of complications in our study is high; which can be due to the fact that our study population comprised entirely of patients with complete deficits. It has been shown that postoperative complications such as infections are common in patients with SCI, even more so in patients with complete SCI.[18, $\underline{30}]$ Previous reports have also suggested that incidence of post-operative complications especially wound infection is even higher in our population. $[\underline{27}, \underline{29}, \underline{32}]$

We noticed several demographic differences in our patients. It has been suggested that whereas RTA are the leading cause of SCI in developed nations, in developing countries fall is a significant cause too, a pattern that was also observed in our study.[17,22] Twenty to $57 \%$ of patients with spinal cord injury have been shown to have significantly associated injuries, typically involving head or chest $[\underline{9}, \underline{15}, \underline{24}, \underline{25}]$ and isolated SCI occurs in only $20 \%$ of patients.[] ] However, this trend is mainly seen in patients with RTA and at our center, almost half of patients sustained their injuries through falls and assault, thus the proportion of patients with isolated spinal injuries in our study is comparatively high.

A similar case study presented itself following the earthquake in Pakistan in 2005 when a large number of spinal cord injuries, with little resources and lack of proper surgical facilities in the area, forced surgeons to test non-operative management to its fullest. Preliminary data from the study supports our findings of higher rates of complications in patients who underwent surgery. $[\underline{29}, \underline{32}]$

Our analysis shows that spinal injury patients with complete deficits who underwent stabilization procedures took longer time for rehabilitation, had longer hospital stay including longer length of stay in intensive care unit and special care unit and were associated with more complications, especially those related to infections. Surgical stabilization was associated with persistent back pain on follow ups. The cost of treatment was also significantly high in the operative group. We recommend that patients with complete SCI should be managed non-operatively with a provision of surgery only if they remain symptomatic.

Publication of this manuscript has been possible by an educational grant from

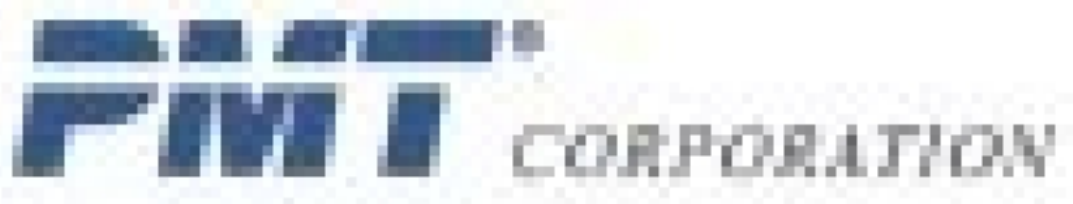

Web site: www.pmtcorp.com 
Available FREE in open access from: http://www.surgicalneurologyint.com/text.asp?2011/2/1/166/90027

\section{REFERENCES}

1. Bagnall AM, Jones L, Duffy S, Riemsma RP. Spinal fixation surgery for acute traumatic spinal cord injury. Cochrane Database Syst Rev. 2008:CD004725. [ubMed]

2. Bedbrook GM. Spinal injuries with tetraplegia and paraplegia. J Bone Joint Surg Br. 1979;61-B:267-84. [PubMed]

3. Bedbrook GM, Sakae T. A review of cervical spine injuries with neurological dysfunction. Paraplegia. 1982;20:321-33. [PubMed]

4. Bedbrook GM, Sedgley GI. The management of spinal injuries--past and present. Int Rehabil Med. 1980;2:45-61. [PubMed]

5. Benzel EC, Larson SJ. Functional recovery after decompressive operation for thoracic and lumbar spine fractures. Neurosurgery. 1986;19:772-8. [PubMed]

6. Burney RE, Maio RF, Maynard F, Karunas R. Incidence, characteristics, and outcome of spinal cord injury at trauma centers in North America. Arch Surg. 1993;128:596-9. [PubMed]

7. Cohen ME, Ditunno JF, Jr, Donovan WH, Maynard FM., Jr A test of the 1992 international standards for neurological and functional classification of spinal cord injury. Spinal Cord. 1998;36:554-60. [PubMed]

8. Collins WF. A review and update of experiment and clinical studies of spinal cord injury. Paraplegia. 1983;21:204-19. [PubMed]

9. Exner G, Meinecke FW. Trends in the treatment of patients with spinal cord lesions seen within a period of 20 years in German centers. Spinal Cord. 1997;35:415-9. [PubMed]

10. Frankel HL, Hancock DO, Hyslop G, Melzak J, Michaelis LS, Ungar GH, et al. The value of postural reduction in the initial management of closed injuries of the spine with paraplegia and tetraplegia. I. Paraplegia. 1969;7:179-92. [PubMed]

11. Geisler FH. Acute management of cervical spinal cord injury. Md Med J. 1988;37:525-30. [PubMed]

12. Guttmann L. Edinburgh, UK: Royal College of Surgeons; 1963. Initial treatment of traumatic paraplegia and tetraplegia.Spinal Injuries Symposium.

13. Guttmann L. 2nd ed. UK: Oxford; 1976. Spinal Cord Injuries: Comprehensive Mangement and Research. 
14. Hansebout RR, Kuchner EF, Romero-Sierra C. Effects of local hypothermia and of steroids upon recovery from experimental spinal cord compression injury. Surg Neurol. 1975;4:531-6. [ubMed]

15. Harris P. Acute spinal cord injury patients--Who cares? Paraplegia. 1985;23:1-7. [PubMed]

16. Heiden JS, Weiss MH, Rosenberg AW, Apuzzo ML, Kurze T. Management of cervical spinal cord trauma in Southern California. J Neurosurg. 1975;43:732-6. [리Med]

17. Hoque MF, Grangeon C, Reed K. Spinal cord lesions in Bangladesh: An epidemiological study 1994-1995. Spinal Cord. 1999;37:858-61. [PubMed]

18. Krassioukov AV, Furlan JC, Fehlings MG. Medical co-morbidities, secondary complications, and mortality in elderly with acute spinal cord injury. J Neurotrauma. 2003;20:391-9. [PubMed]

19. Levi L, Wolf A, Rigamonti D, Ragheb J, Mirvis S, Robinson WL. Anterior decompression in cervical spine trauma: Does the timing of surgery affect the outcome? Neurosurgery. 1991;29:216-22. [ubMed]

20. M S. London: Spinal Injuries Association; 1999. Making the difference: Efficacy of specialist versus nonspecialist management of spinal cord injury.

21. Marshall LF, Knowlton S, Garfin SR, Klauber MR, Eisenberg HM, Kopaniky D, et al. Deterioration following spinal cord injury. A multicenter study. J Neurosurg. 1987;66:400-4. [ubMed]

22. Martins F, Freitas F, Martins L, Dartigues JF, Barat M. Spinal cord injuries--Epidemiology in Portugal's central region. Spinal Cord. 1998;36:574-8. [PubMed]

23. McKinley W, Meade MA, Kirshblum S, Barnard B. Outcomes of early surgical management versus late or no surgical intervention after acute spinal cord injury. Arch Phys Med Rehabil. 2004;85:1818-25. [PubMed]

24. Meguro K, Tator CH. Effect of multiple trauma on mortality and neurological recovery after spinal cord or cauda equina injury. Neurol Med Chir (Tokyo) 1988;28:34-41. [릴ed]

25. Meinecke FW. "Pelvis and limb injuries in patients with recent spinal cord injuries" Proc Veterans Adm Spinal Cord Inj Conf. 1973:205-13. [PubMed]

26. Panjabi MM, Thibodeau LL, Crisco JJ, 3rd, White AA., 3rd What constitutes spinal instability? Clin Neurosurg. 1988;34:31339. [PubMed]

27. Pishori T, Siddiqui AR, Ahmed M. Surgical wound infection surveillance in general surgery procedures at a teaching hospital in Pakistan. Am J Infect Control. 2003;31:296-301. [PubMed] 

28. Pointillart V, Petitjean ME, Wiart L, Vital JM, Lassie P, Thicoipe M, et al. Pharmacological therapy of spinal cord injury during the acute phase. Spinal Cord. 2000;38:71-6. [PubMed]

29. Rathore MF, Farooq F, Butt AW, Gill ZA. An update on spinal cord injuries in October 2005 earthquake in Pakistan. Spinal Cord. 2008;46:461-2. [PubMed]

30. Rechtine GR, Bono PL, Cahill D, Bolesta MJ, Chrin AM. Postoperative wound infection after instrumentation of thoracic and lumbar fractures. J Orthop Trauma. 2001;15:566-9. [PubMed]

31. Sayer FT, Kronvall E, Nilsson OG. Methylprednisolone treatment in acute spinal cord injury: The myth challenged through a structured analysis of published literature. Spine J. 2006;6:335-43. [uㅏMed]

32. Tauqir SF, Mirza S, Gul S, Ghaffar H, Zafar A. Complications in patients with spinal cord injuries sustained in an earthquake in Northern Pakistan. J Spinal Cord Med. 2007;30:373-7. [Mㅡ free article] [PubMed]

33. Vaccaro AR, Daugherty RJ, Sheehan TP, Dante SJ, Cotler JM, Balderston RA, et al. Neurologic outcome of early versus late surgery for cervical spinal cord injury. Spine. 1997;22:2609-13. [PubMed]

34. Wilberger JE. Diagnosis and management of spinal cord trauma. J Neurotrauma. 1991;8(Suppl 1):S21-8. discussion S29-30. [PubMed]

Articles from Surgical Neurology International are provided here courtesy of Wolters Kluwer -- Medknow Publications 